\title{
O REGISTRO CIVIL DAS PESSOAS NATURAIS CONTRIBUINDO PARA A CONCRETIZAÇÃO DA CIDADANIA E DA DIGNIDADE DA PESSOA HUMANA
}

\author{
GUSTAVO HENRIQUE MATTOS VOLTOLINI* \\ RICARDO DOS REIS SILVEIRA**
}

\section{Resumo}

A Constituição Federal de 1988 estabelece como fundamentos da República Federativa do Brasil, dentre outros, a cidadania e a dignidade da pessoa humana. Tais direitos, pelo menos nas serventias extrajudiciais de Registro Civil das Pessoas Naturais, são concretizados ao se realizar gratuitamente os registros de nascimento e de óbito, bem como expedir as primeiras certidões. Para os reconhecidamente pobres também são expedidas gratuitamente as demais certidões e feitos outros registros. Pelo menos nesse quesito a Constituição brasileira, na classificação de Karl Loewenstein, pode ser considerada normativa.

Palavras-chave: Cidadania. Dignidade da pessoa humana. Registro civil das pessoas naturais. Registro de Nascimento. Constituição.

\section{THE CIVIL REGISTRY OF INDIVIDUALS CONTRIBUTING TO THE CONCRETIZATION OF CITIZENSHIP AND HUMAN DIGNITY}

\begin{abstract}
The Federal Constitution of 1988 establishes, among others, the foundation of the Federative Republic of Brazil, the citizenship and the human dignity. These rights, at least in the extra-judicial services of the Civil Registry of Individuals, are fulfilled by the registration of birth and death certificates, as well as issuing the first certificates. For the admittedly poor, other certificates and other records are also issued free of charge. At least in this respect the Brazilian Constitution, in the classification of Karl Loewenstein, can be considered normative.
\end{abstract}

Keywords: Citizenship. Human Dignit. Civil Registry of Individuals. Birth Record. Constitution.

\footnotetext{
* Mestrando em Direitos Coletivos e Cidadania pela Universidade de Ribeirão Preto (UNAERP), Pós-graduado em Direito Civil pela Faculdade Internacional Signorelli (FISIG) graduado em Direito pela Universidade Federal de Santa Catarina (UFSC), Oficial de Registro de Imóveis, Títulos e Documentos, Civil de Pessoa Jurídica e Civil das Pessoas Naturais e de Interdições e Tutelas da Sede da Comarca de Colina/SC. gustavovoltolini@hotmail.com

${ }_{* *}^{*}$ Graduado em Ciências Jurídicas pela Universidade Federal de Ouro Preto - UFOP (1999), Mestre em Filosofia e Metodologia das Ciências pela Universidade Federal de São Carlos - UFSCAR (2003), Doutor em Filosofia e Metodologia das Ciências pela Universidade Federal de São Carlos - UFSCAR (2010). Atualmente é Advogado em Ribeirão Preto, Professor do Programa de Mestrado em Direitos Coletivos e Cidadania da Universidade de Ribeirão Preto - UNAERP, Professor Adjunto do Curso de Direito da Universidade de Ribeirão Preto UNAERP. Possui experiência com Filosofia, Teoria do Estado, Direito Constitucional, Direito do Trabalho e Direito Processual do Trabalho. Mantém o grupo de pesquisa sobre Jurisdição Constitucional e direitos coletivos
} 


\section{INTRODUÇÃO}

O presente trabalho tem por objetivo abordar o tema da possível contribuição dos Registros Civil das Pessoas Naturais para a concretização da cidadania e da dignidade da pessoa humana.

Assim, pretende-se verificar como a realização de atos gratuitos pelo Oficial de Registro das Pessoas Naturais, como os registros de nascimento e de óbito, pode ajudar na concretização da cidadania e da dignidade da pessoa humana e fazer com que a Constituição brasileira possa ser classificada como normativa.

Na primeira parte abordar-se-á, brevemente, sobre a dignidade da pessoa humana, a cidadania, a gratuidade dos atos necessários ao exercício da cidadania e a classificação da Constituição proposta por Karl Loewenstein.

Posteriormente, analisar-se-á as serventias extrajudiciais, sua previsão constitucional e disciplina legal, espécies, atribuições e funções desempenhadas, especialmente o registro civil das pessoas naturais.

Por fim, verificar-se-á que são garantidos a todos a gratuidade dos registros de nascimento e de óbito e a primeira certidão respectiva, bem como aos reconhecidamente pobres as demais certidões, e como tais gratuidades contribuem para concretizar a cidadania e a dignidade da pessoa humana.

O presente artigo tem como metodologia pesquisa documental bibliográfica, consistente em livros de doutrina, artigos e análise da legislação vigente. Utilizar-se-á o método dedutivo, em que se parte da premissa maior para compreender situações particulares, isto é, parte-se do geral para se aplicar a um caso específico.

\section{A CIDADANIA}

Classicamente, cidadania é definida como a qualidade da pessoa nacional, isto é, do brasileiro, de estar no gozo dos direitos políticos (de votar e de ser votado) e ser participante da vida do Estado. (SILVA, 2007) 
A Constituição Federal de 1988, por seu turno, estabelece como fundamentos da República Federativa do Brasil, dentre outros, a cidadania e a dignidade da pessoa humana (art. $1^{\mathrm{o}}$, incisos II e III).

Estabelece, também, a Constituição, em seu artigo 5º inciso LXXVII, que são gratuitos, na forma da lei, os atos necessários ao exercício da cidadania. Tal dispositivo foi regulamentado pela Lei n. 9 9.265/1996, a qual considera ato necessário ao exercício da cidadania, dentre outros, o registro civil de nascimento e o assento de óbito, bem como a primeira certidão respectiva.

Pode-se afirmar que a Constituição não considera mais a cidadania como simples qualidade de gozar direitos políticos. O conceito de cidadania foi ampliado e enriquecido, tendo na dignidade da pessoa humana sua maior racionalidade e sentido. (MAZZUOLI, 2001)

Luiz Alberto David Araújo e Vidal Serrano Nunes Júnior compartilham de tal opinião, ao afirmarem que a cidadania referida na Constituição vai além do direito de votar e ser votado e se aproxima do conceito de cidadania proposto por Hannah Arendt:

\begin{abstract}
A expressão cidadania, aqui indicada como fundamento da República, parece não se resumir à posse de direitos políticos, mas, em acepção diversa, parece galgar significado mais abrangente, nucleado na ideia, expressa por Hannah Arendt, do direito a ter direitos. Segue-se, nesse passo, que a ideia de cidadania vem intimamente entrelaçada com a de dignidade da pessoa humana. (ARAÚJO; VIDAL, 2004, p. 79)
\end{abstract}

Desta forma, a cidadania, como o direito a ter direitos, relaciona-se com a ideia de dignidade da pessoa humana. Há uma mudança de paradigma e o ordenamento jurídico passa a proteger, prioritariamente, a pessoa, não mais o patrimônio. Nesse sentido:

A proteção à dignidade da pessoa foi elevada à condição de fundamento da República Federativa do Brasil, colocando a pessoa como o centro do sistema jurídico, havendo uma inversão de paradigmas, ou seja, de uma ordem patrimonialista passou-se a uma ordem personalista. (SARTURI, 2014)

O foco de todo sistema jurídico é deslocado para a pessoa. O Estado existe para melhorar a vida das pessoas, estas devem ser protegidas e amparadas. Os cidadãos são o fim do Direito. Referindo-se a Kant, Fernando Ferreira dos Santos escreve que:

Em Kant (...) o que caracteriza o ser humano, e o faz dotado de dignidade especial é que ele nunca pode ser meio para os outros, mas fim em si mesmo. (...) Consequentemente, cada homem é fim em si mesmo. E se o texto constitucional diz que a dignidade da pessoa humana é fundamento da República Federativa do Brasil, 
importa concluir que o Estado existe em função de todas as pessoas e não estas em função do Estado. (SANTOS, 1988)

Tratar o cidadão com dignidade, portanto, é considerá-lo um fim em sim mesmo e não um meio em favor do Estado, do Direito ou de quem quer que seja. Estes é que são meios para garantir a dignidade das pessoas.

A cidadania está, como se percebe, intimamente ligada à dignidade da pessoa humana. Não basta dar o poder de votar e ser votado ao cidadão. Este deve ser tratado humanamente, deve ser dado o devido respeito a ele. Para Claudia Adriele Sarturi:

\begin{abstract}
O respeito devido à pessoa humana e a sua dignidade deve colocá-la ao abrigo de tratamentos desumanos ou degradantes. O estado deve dispor de meios que assegurem o bem estar de seus cidadãos e os meios de subsistência necessários. O princípio da dignidade da pessoa humana deve ser a base e fundamento do Estado Democrático de Direito. (SARTURI, 2014)
\end{abstract}

A cidadania, por conseguinte, passa a abranger não só direitos políticos, mas também outros direitos. Tais direitos devem ser previstos no ordenamento jurídico e concretizados na prática. De acordo com o professor Valerio de Oliveira Mazzuoli:

O cidadão, torna-se, então, aquele indivíduo a quem a Constituição confere direitos e garantias - individuais, políticos, sociais, econômicos e culturais -, e lhe dá o poder de seu efetivo exercício, além de meios processuais eficientes contra a violação de seu gozo ou fruição por parte do Poder Público. (MAZZUOLI, 2001)

Deve-se garantir o bem estar do cidadão, bem como a subsistência da população. Sem dignidade não há que se falar em cidadania. Os dois fundamentos da República brasileira devem caminhar juntos.

Neste mesmo sentido é a ideia desenvolvida pelo sociólogo Thomas Humphrey Marshall (1967). Para ele a cidadania vai além dos direitos políticos, já que envolve elementos/direitos civis (como as liberdades individuais) e sociais (como um mínimo de bemestar econômico e segurança).

Igualmente, José Joaquim Calmon de Passos considera que para se alcançar a cidadania plena, faz-se necessário atribuir direitos ao cidadão em três dimensões: política, civil e social:

Correto, por conseguinte, falarmos numa dimensão política, numa dimensão civil e numa dimensão social da cidadania. Ser cidadão implica na efetiva atribuição de direitos nas três esferas mencionadas, porque careceria de sentido participar do 
governo sem condições de fazer valer a própria autonomia, bem como sem dispor de instrumentos asseguradores das prestações devidas pelo Estado, em nome da igualdade de todos. (PASSOS, 2005, p. 14)

Vê-se que a cidadania e a dignidade da pessoa humana constam expressamente no texto da Constituição Federal, mas deve-se analisar se é dado efetividade ao texto constitucional na prática. Se os direitos garantidos são concretizados.

Neste sentido, vale destacar a classificação das constituições sugerida por Karl Loewenstein. Para ele, há constituições normativas, nominais e semânticas. As Constituições normativas têm plena eficácia e efetividade na realidade social, sendo cumpridas pelos detentores do poder e do processo político, bem como sendo inseridas no meio social, isto é, há uma simbiose entre a Constituição e a comunidade do país. Já as Constituições nominais ou nominativas possuem validade jurídica, mas não efetividade existencial. As Constituições semânticas, por sua vez, procuram formalizar o poder político em benefício dos detentores dos fatores reais de poder. (FURIAN, 2014)

Assim, passa-se a analisar como as serventias extrajudiciais de registro civil das pessoas naturais podem contribuir para que os direitos de dignidade da pessoa humana e cidadania, principalmente no que se refere à garantia de gratuidade aos atos necessários ao exercício da cidadania, sejam efetivados ao se realizar registros gratuitos, fazendo com que, pelo menos nesse aspecto, a Constituição brasileira possa ser classificada como uma Constituição normativa.

\section{O REGISTRO CIVIL DAS PESSOAS NATURAIS}

De acordo com o artigo 236 da Constituição Federal, os serviços notariais e de registro são exercidos em caráter privado, por delegação do Poder Público. Ou seja, tais serviços não são prestados diretamente pelo Estado, mas sim pelos delegatários, denominados oficiais de registro e tabeliães. É o que explica Luiz Guilherme Loureiro:

Atividades notariais e de registro constituem funções públicas que, por força do disposto no art. 236 da Constituição, não são executados diretamente pelo Estado, mas por meio de delegação a particulares. Os notários ou registradores, portanto, são profissionais do direito que exercem uma função pública delegada pelo Estado. Tais atividades são desempenhadas em caráter privado, sem que os profissionais que as exerçam integrem o corpo orgânico do Estado. (LOUREIRO, 2014. p. 1) 
O ingresso na atividade notarial e de registro se dá por concurso público de prova e títulos (art. 236, § $3^{\circ}$ ) e os tabeliães e oficiais de registro são agentes públicos, eis que prestam um serviço público delegado a eles por meio de concurso público.

Graças ao concorrido e seletivo concurso público de provas e títulos, prestigia-se a atividade notarial e registral que passa a ser desempenhada por profissionais com formação jurídica, com competência para estarem à frente da função e contribuindo, ainda mais, para a garantia da segurança jurídica dos atos ali praticados. (KÜMPEL, 2013)

Contudo, os tabeliães e oficiais de registro não recebem remuneração do Poder Público, possuem apenas o direito de serem titulares da delegação e receberem os emolumentos que arrecadarem pelos serviços prestados.

Deste modo, os tabeliães e oficiais de registro não são servidores públicos nem concessionários ou permissionários de serviço público, são uma categoria sui generis, por isso disciplinada de forma individualizada no mencionado artigo 236 da Constituição Federal. Nesse sentido, destaca Rafael Maffini:

Eis sua condição híbrida, na medida em que não são nem servidores, nem concessionários, embora possuam os notários e registradores características que ora os aproximam dos servidores públicos ora dos concessionários. Estreme de dúvidas, ao menos neste sentido, se polarizarmos, de um lado, os servidores públicos em sentido estrito e, de outro, os concessionários de serviços públicos, a função notarial e registral caracterizará tertium genus. (MAFFINI, 2015, p.181)

As atividades notariais e de registro são de titularidade do Estado, porém a pessoa jurídica de direito público não a exerce diretamente, sendo tais atividades delegadas ao particular (LOREIRO, 2014), que é necessariamente pessoa natural, não podendo ser pessoa jurídica.

A Lei n. ${ }^{\circ}$ 8.935/1994 disciplina as atividades exercidas pelos oficiais de registro e tabeliães. De acordo com a mencionada lei, os tabeliães, também chamados de notários, e os oficiais de registro, também denominados registradores, são profissionais do direito, dotados de fé pública, a quem é delegado o exercício da atividade notarial e de registro. Tal atividade visa a garantir a publicidade, autenticidade, segurança e eficácia dos atos jurídicos (arts. $1^{\circ}$ e $\left.3^{\circ}\right)$.

São as seguintes as espécies mais comuns de serventias extrajudiciais: tabelião de notas e tabelião de protestos de títulos (atividades notariais) e oficial de registro de imóveis, 
oficial de registro de títulos e documentos e civil das pessoas jurídicas e oficiais de registro civil das pessoas naturais e de interdições e tutelas (atividades registrais), Além desses mais comuns, há também os oficias de registro de distribuição e tabeliães e oficiais de registros de contratos marítimos, conforme estabelecido no artigo $5^{\circ}$ da Lei n. ${ }^{\circ}$ 8.935/1994.

A fiscalização da atividade notarial e registral é exercida pelo Poder Judiciário, conforme estabelecido no artigo 236, § $1^{\circ}$, da Constituição Federal. O $\S 2^{\circ}$, por sua vez, dispõe que é de competência da União, por meio de lei federal, a edição de normas gerais para a fixação de emolumentos relativos aos atos praticados pelos serviços notarias e registrais. Assim, a Lei Federal n. ${ }^{\circ}$ 10.169/2000 estabelece normais gerais para a fixação de emolumentos. (SANTOS, 2006)

Enquanto a União estabelece normas gerais para fixação dos emolumentos, cada Estado e o Distrito Federal efetivamente estabelecem o valor dos emolumentos. Compete também aos Estados e ao Distrito Federal estabelecer forma de compensação aos registradores civis das pessoas naturais pelos atos gratuitos por eles praticados (artigos $1^{\circ}$ e $8^{\circ}$ da Lei 10.169/2000).

No Estado de São Paulo criou-se um fundo para compensação dos atos gratuitos e complementação da renda das serventias deficitárias. Conforme previsto no artigo 19 da Lei Estadual n. ${ }^{\circ} 11.331 / 2002,3,289473 \%$ dos emolumentos devidos pela prestação dos serviços cartoriais pelos atos de Notas e de Registro de Imóveis, de Registro de Títulos e Documentos e Registro Civil das Pessoas Jurídicas e de Protesto são destinados ao fundo para compensação dos atos gratuitos do registro civil das pessoas naturais e à complementação da receita das serventias deficitárias. O fundo é gerido pelo Sindicato dos Notários e Registradores do Estado de São Paulo - SINOREG. A Fazenda Pública não gasta recursos com o ressarcimento de atos gratuitos nem com subsídio para as pequenas serventias que não possuem receita para se manterem.

O Registro Civil das Pessoas Naturais é, dentre as serventias extrajudiciais, aquela que recebeu atribuição para tutela fundamental do cidadão nos atos básicos e fundamentais norteadores da dignidade da pessoa humana. (KÜMPEL, 2014)

Aos oficiais de registro das pessoas naturais, por sua vez, compete fazer registros de nascimento (livro A), casamento (livro B), casamento religioso para efeitos civis (livro B Auxiliar), óbitos (livro C), natimortos (livro C Auxiliar) e proclama (livro D), conforme 
previsto nos artigos 29 e 33 da Lei n. ${ }^{\circ}$ 6.015/1973, chamada Lei de Registros Públicos. Tais atos são praticados por todos os oficiais de registro das pessoas naturais.

Além dessas atribuições e desses livros de todos os oficiais de registros das pessoas naturais, o oficial do $1^{\circ}$ Ofício ou da $1^{\text {a }}$ subdivisão judiciária da sede da comarca possui o livro E, onde são registrados os demais atos relativos ao estado civil, como emancipações, interdições, sentenças declaratórias de ausência, opções de nacionalidade (artigo 33, parágrafo único, da Lei n. ${ }^{\circ}$ 6.015/1973), traslados de assentos de nascimento, casamento e óbito de brasileiros lavrados em país estrangeiro (art. 32 da Lei n. ${ }^{\circ}$ 6.015/1973), união estável (Provimento $\mathrm{n}^{\mathrm{o}} 37$ do Conselho Nacional de Justiça - CNJ).

Todo brasileiro tem contato, ou pelo menos deveria ter, ao menos duas vezes com o Registro Civil das Pessoas Naturais, uma ao nascer, ocasião em que é registrado o seu nascimento e outra ao morrer, para registrar seu falecimento. Sobre o tema afirma Aricele Julieta Costa de Araujo:

No que se refere ao Registro Civil das Pessoas Naturais, este é de indubitável importância para a vida em sociedade, pois estão escriturados os fatos importantes da vida do indivíduo: nascimento, casamento (e suas alterações) e morte. Enfim, o princípio e o fim da personalidade humana. (ARAUJO, 2013)

Diante da importância do Registro Civil das Pessoas Naturais, que acompanha o cidadão desde o seu nascimento, registrando fatos importantes da importantes da vida até sua morte, deve o cartório estar próximo da população. Assim, em cada município deve haver, no mínimo, um oficial de registro civil das pessoas naturais. E nos municípios de significativa extensão territorial, a juízo do respectivo Estado, cada sede distrital igualmente também disporá de, no mínimo, um oficial de registro civil das pessoas naturais (art. 44 , $\S \S 2^{\circ}$ e $3^{\circ}$, da Lei n. ${ }^{\circ}$ 8.935/1994). Portanto, fica constatada a presença do registro civil das pessoas naturais em todos os municípios do Brasil, o que denota a importância do serviço prestado.

Deste modo, passa-se a analisar como o registro civil das pessoas naturais, principalmente por meio do registro de nascimento, contribui para concretizar a cidadania e garantir a dignidade da pessoa humana. 


\title{
4 O REGISTRO CIVIL DAS PESSOAS NATURAIS CONTRIBUINDO PARA A CONCRETIZAÇÃO DA CIDADANIA E DA DIGNIDADE
}

O Brasil, para garantir seu desenvolvimento social, começou a se preocupar cada vez mais com o sub-registro, isto é, com a falta de registro de nascimento de brasileiros. Tais pessoas sem registro vivem em situação de informalidade. Rafael Pinheiro Cavalcanti Guimarães cita os casos que ocasionam o sub-registro:

\begin{abstract}
A desinformação, descaso, desconhecimento, as mais diversas causas, podem levar à situação do sub-registro, situação em que a pessoa não possui assento de nascimento, não sendo contabilizada para fins de políticas públicas, situação que no extremo impossibilita a criança de estudar, tirar documentos e exercer os mais básicos direitos garantidos pela Constituição. Ciente deste problema, o Estado brasileiro mobilizou-se em torno do objetivo de erradicação do sub-registro civil de nascimento, mobilização esta que atua em duas frentes, primeiramente no estímulo de registro de nascimento das crianças recém-nascidas logo após o parto, [...]; secundariamente buscou-se solucionar o problema daqueles que deveriam ter sido registrados e não o foram [...]. (GUIMARÃES, 2015)
\end{abstract}

Por conseguinte, o acesso ao registro de nascimento deveria ser estimulado e facilitado, para o bem do país, que conheceria realmente sua população e poderia desenvolver políticas públicas com mais propriedade, e para o bem da própria população, que sairia da informalidade e poderia concretizar outros direitos que necessitam da comprovação da realização do registro de nascimento.

Com esse intuito, estabelece a Constituição Federal em seu artigo $5^{\circ}$, inciso LXXVI que "são gratuitos para os reconhecidamente pobres, na forma da lei: a) o registro civil de nascimento; b) a certidão de óbito”.

O texto legal possui uma impropriedade técnica ao equiparar os conceitos de registro e certidão. Registro é a inscrição de um fato ou ato em livros que ficam arquivados nas serventias e certidão é um documento que é entregue ao solicitante para comprovar que foi realizado um determinado registro. Luiz Guilherme Loureiro (2014, p. 51) explica que: “certidões são cópias fieis e autenticadas de aos ou fatos constantes dos registros e documentos da serventia. O registrador somente pode certificar o que existe formalmente nos livros e documentos oficiais do serviço.” Assim, é realizado para cada pessoa um registro de nascimento, por exemplo, mas podem ser expedidas inúmeras certidões desse registro de nascimento realizado, bastando solicitação de qualquer pessoa. 
Parece que a intenção do constituinte foi garantir a gratuidade aos reconhecidamente pobres não só do registro de nascimento como também das certidões dele extraídas e não só das certidões como também do registro de óbito. Tanto que a Lei n. ${ }^{\circ}$ 7.844/1989, que disciplinou o mencionado artigo da Constituição, alterou o artigo 30 da Lei de Registros Públicos e estabeleceu que para as pessoas reconhecidamente pobres não serão cobrados emolumentos pelo registro civil de nascimento e pelo assento (registro) de óbito e respectivas certidões.

Contudo, para facilitar ainda mais o acesso aos registros civis das pessoas naturais, a Lei n. ${ }^{0}$ 9.534/1997 alterou novamente o artigo 30 da Lei de Registros Públicos (redação atual) e ampliou a gratuidade dos registros de nascimento e óbito, bem como da primeira certidão, para todos. Além disso, os reconhecidamente pobres estão isentos do pagamento de emolumentos pelas demais certidões que requererem, bem como pelos outros registros, como o registro de casamento, por exemplo.

Atualmente, portanto, o cidadão, independentemente de sua classe social, não paga qualquer valor para realizar registros de nascimentos e óbitos e obter a primeira certidão que comprova a realização de tais registros.

Para garantir o cumprimento da gratuidade dos registros de nascimento e de óbito, estabeleceu o legislador que deve ser afixada na serventia, em local de grande visibilidade e que permita fácil leitura, informações sobre a gratuidade (art. $30, \S 3^{\circ}$-C, da Lei 6.015/1973), podendo o descumprimento da gratuidade ocasionar até mesmo extinção da delegação do Oficial de Registro. Nas palavras de Barbara Tuyama Sollero:

\footnotetext{
A gratuidade dos atos praticados pelo registro civil de pessoas naturais é tratada com indiscutível seriedade pela Lei 6.015/73, a qual veda a inserção, nas certidões, de expressões que indiquem a condição de pobreza e torna obrigatória a exibição, em local de grande visibilidade, de informações claras a respeito da gratuidade. O oficial do cartório que descumprir a gratuidade está sujeito a sanções, inclusive a perda da delegação. (SOLLERO, 2014)
}

No Estado de São Paulo, a gratuidade dos registros de nascimento e óbito é um exemplo de políticas públicas que podem ser realizadas para melhorar a vida da população sem que impliquem custos para o Estado, já que os custos para ressarcir os atos gratuitos 
saem de porcentagem dos emolumentos pagos por outros atos notariais e registrais e não dos cofres públicos.

Com relação ao registro de nascimento, tal alteração visou a erradicar o sub-registro e a garantir que todos tivessem acesso ao mencionado registro, documento imprescindível para a pessoa viver com dignidade. Para ilustrar, Alessandro Marques de Siqueira faz um paralelo do sub-registro com a obra Vidas Secas, de Graciliano Ramos:

\begin{abstract}
A prerrogativa da gratuidade vem para espancar realidades como a narrada na obra Vidas Secas, em que os filhos do casal central da história são simplesmente “filho mais velho" e "filho mais moço". Deixa, pois, de haver o entrave pecuniário para que seja promovido o Registro Civil. Essa garantia vem ao encontro da necessidade de se assegurar condição de cidadania a toda a população [...]. (SIQUEIRA, 2010)
\end{abstract}

Fica evidente, deste modo, que a realização do registro de nascimento é um ato necessário para a plena cidadania e para que o cidadão tenha dignidade. Neste norte, defende Paulo Henrique Mendonça de Freitas:

Decorre da dignidade da pessoa humana, protoprincípio constitucional (CF/88, art. $1^{\circ}$, III), o dever do Estado de implementar políticas e ações que garantam à pessoa sua identificação e a obtenção da correspondente documentação para o pleno exercício da cidadania (diminuição dos índices de sub-registro). (FREITAS, 2014)

Vários aspectos reforçam a ideia de que o registro de nascimento auxilia a concretizar a cidadania e a garantir a dignidade da pessoa humana. O primeiro aspecto é servir de prova. A personalidade civil da pessoa começa com o nascimento com vida (artigo $2^{\circ}$ do Código Civil) e a prova da ocorrência de tal nascimento se dá com o registro de nascimento e com a certidão dele extraída. É o que afirma Patricia Perruchi:

\footnotetext{
O nascimento com vida é o fato jurídico que permitirá a pessoa ser acolhida pelo direito com a aquisição da personalidade civil. Para provar a sua existência, devese fazer o assentamento da certidão no Registro Civil das Pessoas Naturais válido a todos que nascerem em território nacional. (PERRUCHI, 2016)
}

A certidão de nascimento comprova não só o próprio nascimento, como também o nome completo da pessoa, que a identifica na sociedade. Diante a importância da individualidade humana surge o nome próprio, que compreende o prenome e o sobrenome. $\mathrm{O}$ nome designa a pessoa e é tornado público com o registro civil das pessoas naturais. (SIQUEIRA, 2010) 
Além do nascimento em si e do nome, com a certidão de nascimento se consegue comprovar a idade do registrado, sua filiação e demais parentescos, nacionalidade, naturalidade e se consegue obter outros documentos como a carteira de identidade.

Todos os brasileiros nascidos no Brasil tem seu nascimento registrado gratuitamente no Livro A do Registro Civil das Pessoas Naturais. É um direito do cidadão para efetivar sua cidadania. Sobre o assunto, Antonio Pessoa Cardoso reforça que:

O registro civil é direito humano fundamental que possibilita o exercício da cidadania e a dignidade da pessoa humana; dá nome, individualiza a pessoa; é o primeiro documento na vida do cidadão, comprovante de sua existência no mundo da lei; depois desse documento, e em função dele, consegue-se a carteira de identidade, o título de eleitor, o CPF, a certidão de casamento. (CARDOSO, 2016)

Atualmente, na ocasião da lavratura do registro de nascimento já se expede no Registro Civil das Pessoas Naturais, no mesmo ato e também gratuitamente, o CPF ao registrado. Com isso, se concretiza o texto Constituição, que estabelece que os atos necessários ao exercício da cidadania devem ser gratuitos, garantindo, assim, direitos fundamentais ao cidadão. Sobre o tema, ratifica Raphael Pinheiro Cavalcanti Guimarães:

O registro civil de nascimento é a porta de entrada do cidadão na vida civil, ato base para constituição de todos os demais direitos fundamentais, sem o qual o cidadão fica impedido de exercer os direitos mais básicos de cidadania como saúde e educação, devendo ser absolutamente prioritária a erradicação do sub-registro [...] tudo no intuito de conferir os direitos fundamentais de forma gratuita ao maior número possível de pessoas. (GUIMARÃES, 2015)

A falta do registro de nascimento impede o acesso aos serviços sociais básicos e, em caso de morte da pessoa que não teve seu nascimento registrado, esta é enterrada como indigente. (CARDOSO, 2016)

Fica evidente, desta forma, que a falta de registro de nascimento fere a dignidade da pessoa desde o seu nascimento até a sua morte, eis que em vida é impedida de concretizar diversos direitos que exigem a apresentação de certidão de nascimento e quando falece é enterrada sem dignidade.

Também o registro de óbito gratuito contribui para a concretização da cidadania. Feito o registro de óbito, o particular pode comprovar o falecimento para requerer seus direitos, tais como benefícios previdenciários ou realização de inventário e o poder público 
pode realizar atos importantes como cancelar o título de eleitor, cancelar benefícios previdenciários, fiscalizar o recolhimento do ITCMD devido pela transferência causa mortis, elaborar mapas estatísticos, saber da morte do contribuinte, já que o Oficial de Registro Civil comunica a lavratura de assento de óbito à Justiça Eleitoral, ao INSS, à Fazenda Pública Estadual, ao IBGE e ao Instituto de Identificação (IIRGD), responsável por expedir as carteiras de identidade. Barbara Tuyama Sollero escreve que:

É igualmente salutar incentivar, por meio da gratuidade, o registro do óbito, dada sua relevância, pois marca o fim da personalidade do ser humano. Demais disso, o serviço de registro civil tem o dever de comunicar os óbitos registrados a vários órgãos, repercutindo tal registro em várias áreas. A comunicação ao INSS, por exemplo, servirá para que seja cessado eventual benefício pago ao falecido. O IBGE também é informado dos falecimentos, pois este dado entrará na elaboração dos mapas de mortalidade, que servem para orientar a elaboração de políticas públicas. (SOLLERO, 2014)

Portanto, fica constatada que, no que se refere aos atos praticados no Registro Civil das Pessoas Naturais, os direitos previstos na Constituição Federal são efetivados e com uma política pública exemplar, já que é prestado um serviço gratuito aos cidadãos sem onerar os cofres públicos. Assim, a dignidade da pessoa humana e a cidadania são concretizadas ao se realizar, gratuitamente a todos, os registros de nascimento e de óbito, bem como as respectivas primeiras certidões. E aos reconhecidamente pobres é garantida a gratuidade na expedição das demais certidões e realização de outros registros (como o de casamento, por exemplo).

Diante do exposto, pela política pública desenvolvida para garantir a gratuidade de registros e certidões no Registro Civil das Pessoas Naturais, pode-se afirmar que, pelo menos nesse aspecto, a Constituição brasileira pode ser considerada normativa, já dá plena eficácia e efetividade a garantias constitucionais, sendo a constituição cumprida de modo exemplar.

\section{CONCLUSÃO}

A cidadania e a dignidade da pessoa humana são fundamentos da República Federativa do Brasil e é garantida, pela Constituição, a gratuidade, na forma da lei, dos atos necessários ao exercício da cidadania. A Lei n. 9 9.265/1996 considera o registro civil de nascimento e o assento de óbito, bem como a primeira certidão respectiva, ato necessário ao exercício da cidadania. 
Cidadania e dignidade da pessoa humana passaram a ser considerados conceitos que estão relacionados. A cidadania não é definida mais apenas garantia dada ao nacional de exercer os direitos políticos, isto é, de votar e ser votado.

O conceito de cidadania foi ampliado, passando a abranger, além dos direitos políticos, os direitos civis e sociais. Os cidadãos devem ser tratados com respeito, com dignidade. Só assim pode se falar em cidadania plena.

As serventias extrajudiciais de registro civil das pessoas naturais, por seu turno, concretizam o texto constitucional e efetivam a cidadania, a dignidade da pessoa humana e a gratuidade dos atos necessários ao exercício da cidadania, por meio da gratuidade de registros e certidões, principalmente de nascimento, fazendo com que a Constituição brasileira possa ser classificada, pelo menos em relação a esses aspectos, como uma constituição normativa.

Em cada município deve haver, no mínimo, um oficial de registro civil das pessoas naturais, que realiza, dentre outros atos, o registro de nascimentos, casamentos e óbitos.

A Constituição Federal estabelece que são gratuitos para os reconhecidamente pobres, na forma da lei, os registros de nascimento e de óbito. O artigo 30 da Lei de Registros Públicos e a Lei n. ${ }^{o}$ 9.265/1996 ampliaram a gratuidade dos registros de nascimento e óbito, bem como da primeira certidão, para todos, não apenas os reconhecidamente pobres. Tal gratuidade a todos visou a garantir a dignidade, a cidadania e a reduzir o número de subregistros, de modo a facilitar a acesso aos registros de nascimento e de óbito.

O registro de nascimento gratuito auxilia a concretizar a cidadania e a garantir a dignidade da pessoa humana, já que tal registro: a) prova a ocorrência do nascimento; b) prova o nome, isto é, prenome e sobrenome, que designa e individualiza a pessoa; c) comprova outros dados da pessoa, como a idade do registrado, sua filiação e demais parentescos, nacionalidade e a naturalidade; d) é requisito para se obter outros documentos, como a carteira de identidade. Na falta de registro de nascimento a pessoa sem registro é, em caso de morte, enterrada como indigente.

Atualmente, já se expede CPF no Registro Civil das Pessoas Naturais ao registrado na ocasião da lavratura de registro de nascimento, também de forma gratuita, concretizando a garantia constitucional de gratuidade aos atos necessários ao exercício da cidadania. 
O registro de óbito gratuito igualmente contribui para a concretização da cidadania, eis que: a) comprova o falecimento, podendo ser requerido direitos decorrentes do óbito, como benefícios previdenciários ou realização de inventário; b) o poder público pode cancelar o título de eleitor do falecido, cancelar benefícios previdenciários do de cujus, fiscalizar o recolhimento do ITCMD devido pela transferência causa mortis, elaborar mapas estatísticos, já que o Oficial de Registro Civil comunica a lavratura de assento de óbito à Justiça Eleitoral, ao INSS, à Fazenda Pública Estadual, ao IBGE e ao Instituto de Identificação (IIRGD).

Os reconhecidamente pobres também estão isentos do pagamento de emolumentos pelas demais certidões que requererem, bem como pelos outros registros, como o registro de casamento, por exemplo.

A atividade notarial e registral é fiscalizada pelo Poder Judiciário e o registrador que descumprir gratuidade dos registros de nascimento e de óbito fica sujeito até mesmo a pena de extinção da delegação.

Os emolumentos cobrados pelo exercício da atividade notarial e registral, dentre a qual se encontra o registro civil das pessoas naturais, é fixado por lei estadual, cabendo à União estabelecer de normas gerais, por meio de lei federal. Aos estados também compete estabelecer forma de compensação dos atos gratuitos praticados pelos registradores civis das pessoas naturais.

No Estado de São Paulo a compensação dos atos gratuitos é realizada por meio de um fundo de compensação. Dos emolumentos devidos pela prestação de serviços Notas e de Registro de Imóveis, de Registro de Títulos e Documentos e Registro Civil das Pessoas Jurídicas e de Protesto, 3,289473\% se destinam a tal fundo.

Ao se reconhecer uma firma, lavrar uma escritura ou autenticar uma cópia, por exemplo, 3,289473\% dos emolumentos pagos se destinam ao mencionado fundo, que também se destina à complementação da renda das serventias deficitárias. O Estado não gasta recursos com o ressarcimento de atos gratuitos nem com subsídio para as serventias deficitárias, constituindo-se num modelo de política pública em que há um benefício para o cidadão sem implicar em custos financeiros para o Estado.

Diante do exposto, o Registro Civil das Pessoas Naturais, por meio de serviços gratuitos aos cidadãos que não oneram os cofres públicos, efetiva a cidadania, a dignidade da pessoa humana, a gratuidade dos atos necessários ao exercício da cidadania e o disposto no 
artigo 5º, inciso LXXVI, da Constituição Federal. Assim, por meio da gratuidade a todos dos registros de nascimento e de óbito, bem como as respectivas primeiras certidões, bem como pela gratuidade aos reconhecidamente pobres das demais certidões e realização de outros registros (como o de casamento, por exemplo), pode-se afirmar que, ao menos nesse aspecto, a Constituição pátria pode ser considerada normativa, já que concretiza garantias constitucionais, sendo a constituição cumprida de modo exemplar.

\section{REFERÊNCIAS}

ARAUJO, Aricele Julieta Costa de. A importância e a possibilidade de alteração do nome civil das pessoas naturais. Âmbito Jurídico, Rio Grande, XVI, n. 116, set 2013. Disponível em:

<http://www.ambitojuridico.com.br/site/?n_link=revista_artigos_leitura\&artigo_id=13616>. Acesso em: 20 Jan. 2017.

ARAÚJO. Luiz Alberto David; NUNES JÚNIOR, Vidal Serrano. Curso de Direito Constitucional. 8. ed. rev. e atual. São Paulo: Saraiva, 2004.

BRASIL. Constituição da República Federativa do Brasil do Brasil de 1988. Disponível em: <http://www.planalto.gov.br/ccivil_03/constituicao/ConstituicaoCompilado.htm>. Acesso em: 24 abr. 2017.

. Lei n. ${ }^{0}$ 9.265, de 12 de fevereiro de 1996. Regulamenta o inciso LXXVII do art. $5^{\circ}$ da Constituição, dispondo sobre a gratuidade dos atos necessários ao exercício da cidadania. Disponível em: <http://www.planalto.gov.br/ccivil_03/leis/L9265.htm>. Acesso em: 12 fev. 2017.

. Lei n. ${ }^{\circ}$ 8.935, de 18 de novembro de 1994. Regulamenta o art. 236 da Constituição Federal, dispondo sobre serviços notariais e de registro. (Lei dos cartórios). Disponível em: <http://www.planalto.gov.br/ccivil_03/leis/L8935.htm>. Acesso em: 24 abr. 2017.

Lei n. ${ }^{\mathbf{0}}$ 10.169, de 29 de dezembro de 2000. Regula o § 2o do art. 236 da Constituição Federal, mediante o estabelecimento de normas gerais para a fixação de emolumentos relativos aos atos praticados pelos serviços notariais e de registro. Brasília, DF, Disponível em: <http://www.planalto.gov.br/ccivil_03/leis/L10169.htm>. Acesso em: 10 jul. 2017. 
. Lei n..$^{0}$ 7.844, de 18 de outubro de 1989. Disciplina o inciso LXXVI do art. $5^{\circ}$ da Constituição da República Federativa do Brasil, alterando a redação do art. 30 da Lei n 6.015, de 31 de dezembro de 1973. Brasília, DF, Disponível em: < http://www.planalto.gov.br/ccivil_03/leis/L7844.htm>. Acesso em: 10 jul. 2017.

. Lei n. ${ }^{\circ}$ 6.015, de 31 de dezembro de 1973. Dispõe sobre os registros públicos, e dá outras providências. Brasília, DF, Disponível em: <http://www.planalto.gov.br/ccivil_03/leis/L6015original.htm>. Acesso em: 26 jul. 2017.

. Provimento n. ${ }^{\circ} 37$ do Conselho Nacional de Justiça - CNJ, de 07 de julho de 2014. Dispõe sobre o registro de União Estável, no livro E, por Oficial de Registro Civil. Disponível em: $<$ http://www.cnj.jus.br/images/stories/docs_corregedoria/provimentos/provimento_37.pdf>. Acesso em: 10 jul. 2017.

. Lei n. ${ }^{\circ}$ 9.534, de 10 de dezembro de 1997. Dá nova redação ao art. 30 da Lei $\mathrm{n}^{\circ}$ 6.015, de 31 de dezembro de 1973, que dispõe sobre os registros públicos; acrescenta inciso ao art. $1^{\circ}$ da Lei $\mathrm{n}^{\circ}$ 9.265, de 12 de fevereiro de 1996, que trata da gratuidade dos atos necessários ao exercício da cidadania; e altera os arts. 30 e 45 da Lei n ${ }^{\circ} 8.935$, de 18 de novembro de 1994, que dispõe sobre os serviços notariais e de registro. Brasília, DF, Disponível em: <http://www.planalto.gov.br/ccivil_03/leis/L9534.htm>. Acesso em: 10 jul. 2017.

PASSOS, José Joaquim Calmon de. Cidadania Tutelada. In: FERREIRA, Luiz Alexandre Cruz (org.). Hermenêutica, cidadania e direito. Campinas: Millenium, 2005.

CARDOSO, Antônio Pessoa. O registro civil e a cidadania: O sub-registro perdurou por muito tempo entre nós, até que a Constituição de 1988 consagrou a gratuidade dos "atos necessários ao exercício da cidadania.” Migalhas, Brasil, 04 ago. 2016. Disponível em: $<$ http://www.migalhas.com.br/dePeso/16,MI243350,21048O+registro+civil+e+a+cidadania>. Acesso em: 10 jul. 2017.

FREITAS, Paulo Henrique Mendonça de. O Judiciário e os Serviços Notariais e de Registros. Âmbito Jurídico, Rio Grande, XVII, n. 131, dez 2014. Disponível em: $<$ http://www.ambitojuridico.com.br/site/index.php?n_link=revista_artigos_leitura\&artigo_id= 15570\&revista_caderno=7>. Acesso em: 20 Jan. 2017.

FURIAN, Leonardo. Classificação das Constituições conforme Karl Loewenstein. Conteúdo Jurídico, Brasília, 12 nov. 2014. Disponível em: $<$ http://www.conteudojuridico.com.br/?artigos\&ver=2.50603\&seo=1>. Acesso em: 20 jul. 2017.

GUIMARÃES, Raphael Pinheiro Cavalcanti. O procedimento de registro tardio de nascimento à luz da Provimento ${ }^{\circ} 28$ do Conselho Nacional de Justiça. Âmbito Jurídico, Rio Grande, XVIII, n. 142, nov. 2015. Disponível em: 
<http://www.ambitojuridico.com.br/site/index.php?n_link=revista_artigos_leitura\&artigo_id= 16583\&revista_caderno=7>. Acesso em: jan 2017.

KÜMPEL, Vitor Frederico. Evolução histórica da atividade notarial no Brasil. Migalhas, Brasil, 21 maio 2013. Disponível em:

<http://www.migalhas.com.br/Registralhas/98,MI178865,61044-

Evolucao+historica+da+atividade+notarial+no+Brasil>. Acesso em: 10 jul. 2017.

KÜMPEL, Vitor Frederico. O papel do MP no Registro Civil. ARPEN, São Paulo, ano 15, nº 147, mai. 2014.

LOUREIRO, Luiz Guilherme. Registros Públicos: teoria e prática. 5. ed rev. e ampl. Rio de Janeiro: Forense, 2014.

MAFFINI, Rafael. Regulação da função notarial e registral e os limites normativos do Poder Judiciário. Revista de Direito Imobiliário, São Paulo, ano 38, v. 79, dez. 2015.

MARSHALL, Thomas Humphrey. Cidadania e classe social. In: Cidadania, classe social e status. Rio de Janeiro: Zarar, 1967. Cap. 3. p. 57-114. Tradução de Meton Porto Gadelha.

MAZZUOLI, Valério de Oliveira. Direitos humanos, cidadania e educação. Revista Jus Navigandi, Teresina, ano 6, n. 51, 1 out. 2001. Disponível em:

<https://jus.com.br/artigos/2074>. Acesso em: 18 jan. 2017.

PERRUCHI, Patrícia. Registro civil as Pessoas Naturais: Superior Tribunal de Justiça (STJ) decide se retificação de sexo em registro civil exige cirurgia. Jusbrasil, Brasil, 2016.

Disponível em: <https://patperruchi.jusbrasil.com.br/artigos/397124064/registro-civil-aspessoas-naturais>. Acesso em: 10 jul. 2017.

SANTOS, Fernando Ferreira dos. Princípio constitucional da dignidade da pessoa humana. Revista Jus Navigandi, Teresina, ano 3, n. 27,23 dez. 1998. Disponível em: $<$ https://jus.com.br/artigos/160>. Acesso em: 21 jan. 2017.

SANTOS, Reinaldo Velloso dos. Registro civil das pessoas naturais. Porto Alegre: Sergio Antonio Fabris Editor, 2006.

SÃO PAULO. Lei n. ${ }^{\circ}$ 11.331, de 26 de dezembro de 2002. Dispõe sobre os emolumentos relativos aos atos praticados pelos serviços notariais e de registro, em face das disposições da Lei federal $\mathrm{n}^{0}$ 10.169, de 29 de dezembro de 2000. Disponível em:

<http://www.al.sp.gov.br/repositorio/legislacao/lei/2002/lei n.11.331, de 26.12.2002.htm>. Acesso em: 26 jul. 2017.

SARTURI, Claudia Adriele. A Constituição Federal de 1988, o princípio da dignidade da pessoa humana e a redefinição dos institutos de direito privado. Conteúdo Jurídico, Brasília, 01 dez. 2014. Disponível em: 
<http://www.conteudojuridico.com.br/?artigos\&ver=2.51072\&seo=1>. Acesso em: 10 jul. 2017.

SILVA, José Afonso da. Curso de direito constitucional positivo. 29. ed. São Paulo: Malheiros, 2007.

SIQUEIRA, Alessandro Marques de. Registro Civil. Conteúdo Jurídico, Brasília, 18 out. 2010. Disponível em: <http://www.conteudojuridico.com.br/?artigos\&ver=2.29364\&seo=1>. Acesso em: 18 jan. 2017.

SOLLERO, Barbara Tuyama. Atos gratuitos do registro civil de pessoas naturais. Conteúdo Jurídico, Brasília, 03 dez. 2014. Disponível em:

$<$ http://www.conteudojuridico.com.br/?artigos\&ver=2.51112\&seo=1>. Acesso em: 17 jan. 2017. 